\title{
FEMINISMO EM MOVIMENTO: TEMAS E PROCESSOS ORGANIZATIVOS DA MARCHA MUNDIAL DAS MULHERES NO FÓRUM SOCIAL MUNDIAL
}

\author{
MIRIAM NOBRE \\ SOF - Sempreviva Organização Feminista \\ NALU FARIA \\ SOF - Sempreviva Organização Feminista
}

Resumo: O texto apresenta uma comparação entre o surgimento e desenvolvimento do processo Fórum Social Mundial e a Marcha Mundial das Mulheres no Brasil. O Fórum teve uma enorme contribuição para historicizar a globalização capitalista e mudar os termos do debate, e o movimento de mulheres tem sua trajetória imersa neste contexto, assim como o feminismo tem um grande potencial para desnaturalizar o discurso sobre a globalização e a economia neoliberal. O texto também mostra as relações construídas entre os movimentos sociais e suas agendas em comum que vêm se expressando no conjunto das ações do movimento antiglobalização.

Palavras-chave: mulheres, feminismo, movimentos sociais, política.

\section{Mudando os termos do debate}

O Fórum Social Mundial é fruto e seiva do movimento antiglobalização. Indígenas em Chiapas, indocumentados e trabalhadoras públicas na Europa deram os primeiros sinais de reação à afirmação de que não havia alternativa ao neoliberalismo. Em Seattle percebemos a enorme quantidade e a capacidade de organização de grupos que resistiam ao neoliberalismo e a emergência de uma nova geração política. A Marcha Mundial das Mulheres se inicia nesse mesmo contexto e tem pontos em comum com esta nova movimentação: crítica radical ao sistema, formas de organização que articulam o local ao internacional, grandes manifestações públicas. 
O Fórum Social Mundial tem conseguido crescer condensando essas várias formas de luta em uma flecha certeira no coração do sistema: o pensamento único neoliberal e sua máxima "Não há alternativa". Nos anos 1990, as sucessivas crises econômicas e o aumento da pobreza e das desigualdades sociais evidenciavam que as políticas econômicas neoliberais eram péssimas. Os países que seguiram a receita de privatizações, abertura comercial e financeira, comprometimento da economia local e serviços públicos para honrar o pagamento de uma dívida imoral e muitas vezes ilegal estavam de mal a pior. Melhor estavam os países que conseguiram manter algum grau de soberania em suas decisões econômicas, sejam elas comerciais, fiscais ou monetárias.

Porém, quanto mais cresciam as evidências materiais, mais aumentava o tom do discurso que ganhara corações e mentes desde os anos 1980. A expressão "a economia se globaliza" nos dá a ilusão de um movimento de capitais em todas as direções com equivalente distribuição de benefícios. Essa ilusão se constrói primeiro no desaparecimento do sujeito. A moeda de um país era desvalorizada não porque isso interessava a um grupo de especuladores com endereço fixo na city londrina, mas porque os mercados estavam nervosos. Ao que se somava a idéia de que não existem interesses de classe contrapostos, mas interesses difusos. Os fundos de pensão administrados por organizações de representação dos trabalhadores surgem como fonte segura de capital e os investidores do momento. Circulam notícias de velhinhas estadunidenses que se reúnem para um chá e discutem seus investimentos na Bolsa.

Os Estados nacionais onde tradicionalmente se costuram os contratos para vivermos em sociedade são escondidos sob a mesma cortina de fumaça. A uma economia globalizada caberia uma instituição política global. E tem sido assim que o Fundo Monetário Internacional e o Banco Mundial operam, impondo políticas e modelos para educação, saúde, etc. em todos os países que necessitam de seu aval ou de seu dinheiro.

Nos anos 1980 e parte dos 1990 os movimentos sociais estavam imersos nesse discurso. Primeiro na idéia de que não havia uma representação de interesses politicamente construídos, mas dados por uma identidade e que se justapunham uns aos outros em uma sociedade civil. Segundo, que os Estados nacionais não são mais o terreno político prioritário, mas sim as conferências internacionais da ONU e da OEA que estabelecem tratados e convenções. O foco da ação política tornou-se basicamente o campo normativo. Cabe aos Estados assinar o tratado e regulamentá-lo na legislação nacional. Talvez criar uma maquinária nova para implementa-lo, e à sociedade cabe monitorá-lo.

O movimento de mulheres tem sua trajetória imersa nesse contexto. Um debate permanente no feminismo é sobre a centralidade do discurso e do normativo nas relações de poder entre homens e mulheres. O pós-modernismo contribuiu para o desenvolvimento de uma teoria feminista centrada no discurso e nos signos. Mas como essa combinação de pensamento único neoliberal e de uma apreensão limitada da teoria pós-moderna esvaziando o poder dos sujeitos coletivos repercutiu na ação política feminista? Um dos efeitos nos parece ser uma política de resultados: investimento nas Conferências da ONU em seus eventos preparatórios e de seguimento, a demanda por políticas públicas e o empowerment das mulheres como indivíduos. A estratégia central passou a ser encontrar brechas e 'generificar' os espaços de poder, reivindicando o aumento na presença de mulheres e instrumentos de planejamento, monitoramento e avaliação como as intermináveis check list de gênero. Mas enquanto as mulheres se empenhavam na implementação de políticas públicas, a maioria delas focais, e na incorporação do discurso de gênero no Estado, o mercado organizava a vida das mulheres em todos os níveis, inclusive o subjetivo.

A perda do horizonte de transformação das relações de gênero em um contexto 
de transformação geral das relações de poder e exploração da sociedade também significou uma despolitização do debate sobre globalização. Era comum ouvir que a globalização tem dois lados, que cresceu a oportunidade de emprego para as mulheres no mundo todo e que havia diminuído a diferença salarial entre homens e mulheres. Pouco se falava sobre que tipo de emprego era esse, porque a taxa de atividade feminina retrocedeu na 'nova' Rússia, que o salário dos homens vem diminuindo e a diferença salarial entre as mulheres aumentando. Isto é, ao se falar em dois lados justapostos, não se tratava dos movimentos contraditórios e paradoxos da etapa atual do capitalismo em que umas podem ganhar, mas muitas estão perdendo.'

No entanto, o feminismo tem um enorme potencial para desnaturalizar o discurso sobre a globalização e a economia neoliberal. Ao tratarmos as mulheres como sujeitos Ihes restituímos seu corpo e sua história, o que nos remeteria a outros: o marido, o pai, o gerente da maquilladora, até o acionista majoritário da transnacional que decidiu abrir uma sweetshop nas Filipinas para produzir um tênis barato.

O Fórum Social Mundial teve uma enorme contribuição para historicizar a globalização capitalista e mudar os termos do debate. Primeiro trocando o mandamento "Não há alternativa" por "Um outro mundo é possível", isto é, mulheres e homens do mundo inteiro pensando livremente e abandonando o estreito círculo da política de resultados. Em segundo lugar, trazendo à tona temas e sujeitos políticos. O Fórum é mundial, mas recolocou o debate da soberania nacional. Em cada uma de suas edições as 'questões' Colômbia, Venezuela, a resistência ao imperialismo econômico, com a Alca, e militar, a invasão no Iraque foram objeto de debate e solidariedade públicas. O debate sobre direitos tem sido tratado não somente em sua dimensão legal e normativa, mas como a igualdade em seu exercício torna-se um princípio organizador da vida. E que, à capacidade individual de concebê-los, lutar por eles e vivenciá-los, se articulam constrangimentos econômicos, sociais, culturais e políticos.

Nós da Marcha Mundial das Mulheres desde o início nos constituímos como parte do movimento antiglobalização e nos colocávamos o desafio de como fortalecer a presença e a agenda feminista neste movimento de movimentos. O Fórum Social Mundial e a Rede de Movimentos Sociais que nele se criou têm sido nosso terreno privilegiado para construir análises e agendas e para exercitar novas abordagens e formas de organização.

\section{Nossas análises e agendas}

No primeiro FSM, em 2001, nossa intervenção, com uma delegação de mulheres de 20 países, foi centrada em nos apresentar: quem éramos, no que acreditávamos, o que estávamos empenhadas em construir. Pensamos o Fórum como um lugar de construção de reflexão e demos os primeiros passos na articulação dos movimentos sociais.

Durante 2001, a relação com os movimentos sociais cresceu, assim como o debate sobre o caráter de nosso pertencimento a esse ciclo de lutas dos movimentos antiglobalização no interior da Marcha. Isso influenciou nossas análises do cenário político, nossos temas, nossas formas de ação. Em 2002, conseguimos pautar no FSM a discussão sobre a violência contra as mulheres, que foi tema de debate de uma conferência. Nosso propósito foi debater como o machismo e a violência sexista se expressam na realidade cotidiana de todas nós e buscando comprometer os movimentos sociais no seu enfrentamento. Junto com a Rede Mulheres Transformando a Economia nos propusemos, a partir de um debate sobre pobreza, ampliar as discussões de alternativas econômicas

\footnotetext{
${ }^{1}$ Helena HIRATA, 2003, e Danièle KERGOAT, 2000.
} 
feministas à ordem capitalista e patriarcal.

Em 2002, o Fórum Social Mundial cresceu como processo com edições locais, experimentando outras formas de organização como as amplas assembléias rotativas de preparação do Fórum Social Europeu. A agenda comum dos movimentos sociais ganhou concretude, foram criadas relações de confiança no trabalho comum como para nós nas Américas na campanha contra a Alca, foram vencidas provas de fogo como a coordenação de grupos e setores diversos nos momentos de enfrentamento das reuniões do G8, Banco Mundial, FMl, e mesmo da ONU, em Joanhesburgo.

Nosso processo de preparação do FSM também cresceu. Estendemos o debate sobre o Fórum Social Mundial nos vários grupos envolvidos na Marcha, novos grupos se aproximaram de nós a partir do FSM, fizemos maiores conexões entre os temas de combate à pobreza e a violência sexista tendo como eixo o enfrentamento da ditadura do mercado, do pensamento conservador e familista.

No terceiro Fórum tecemos maiores conexões a partir de um olhar sobre a mercantilização. O capitalismo se fundou ao elevar o mercado de um simples espaço/ momento de troca para o centro organizador da vida das pessoas, transformando os fatores de produção, a terra, o capital e o trabalho, eles próprios, em mercadoria. O capitalismo expande as fronteiras do mercado, é possível comprar e vender relações interpessoais, corpos, sentimentos. Como esse movimento se apropria da situação de subordinação das mulheres? Pelo fato de grande parte do trabalho que realizamos no âmbito doméstico e nas relações comunitárias estar fora do mercado, mas sustentar seu funcionamento? Pelo fato de que, nas situações-limite de pobreza e degradação, ainda termos nossos corpos e a capacidade de dar prazer a um homem para ser vendidos? E como esse movimento do mercado que teoricamente retira as individualidades presentes nas trocas ao resumir tudo a um valor em dólar, que nem mesmo existe fisicamente, mas como bytes no computador de um operador da Bolsa, cria condições para a afirmação de identidades nacionais e conservadoras? Essas foram algumas questões que permearam nossos debates aparentemente tão diversos como experiências de economia solidária, publicidade sexista e padrão de beleza, tráfico de mulheres. Nesse contexto reafirmamos o direito ao aborto construindo com as companheiras argentinas do Fórum pelos Direitos Reprodutivos uma declaração que qualifica o mundo que acreditamos ser possível. "Um mundo no qual as mulheres tenham a dignidade de poder optar por uma maternidade desejada e a liberdade de dispor de seu próprio corpo. [...] Somos mulheres e não mercadorias." Essas foram as palavras de ordem de nossas ações públicas, seja nas passeatas de abertura e contra a Alca, seja em nossa passeata no interior do Acampamento da Juventude.

\section{Debate feminista no conjunto do FSM}

Há muitas entradas para se discutir nossa capacidade de fazer com que o discurso feminista, pensado como um projeto global para a humanidade, interaja com o conjunto do Fórum. Temos atuado de forma sistemática no debate sobre desenvolvimento sustentável e alternativas econômicas e estaremos relatando nossos aprendizados nesse campo.

Em 2002, nosso eixo foi o tema do trabalho, não como um tema setorial, mas como o coração da sociedade capitalista. Foi assim no seminário "Mujeres y trabajo: realidades y propuestas para el cambio", realizado em conjunto com a Rede Mulheres Transformando a Economia (REMTE) e o grupo de trabalho de gênero do CLACSO (Conselho LatinoAmericano de Ciências Sociais). Na conferência sobre economia solidária, Rosa Guillén comentou a divisão sexual do trabalho. Na conferência sobre trabalho quase todos os expositores eram sindicalistas com uma visão de trabalho restrita a emprego, na maioria 
das vezes fabril. Sylvia Estrada ampliou a idéia de trabalho comentando o trabalho informal, doméstico e comunitário realizado pelas mulheres, invisível porém fundamental para manter a economia em funcionamento.

Em 2003, durante a preparação do FSM nós da Marcha Mundial das Mulheres propusemos que no eixo sobre desenvolvimento sustentável houvesse um painel sobre uma outra economia. Os temas seriam decorrentes do questionamento ao produtivismo, aos valores de eficiência e competitividade, ao consumismo. Um painel que debatesse a mercantilização da vida, a ideologia neoliberal como base e produto da reorganização da economia capitalista, as maneiras como nossa sociedade vem lidando - ou se esquivando de lidar - com a reprodução social.

Ao final, o painel acordado chamou-se "Por outra economia: subsidiariedade, localização, devolução e reprodução", com o objetivo de questionar padrões centralizadores e patriarcais de desenvolvimento e apresentar estratégias alternativas. Cristina Carrasco apresentou os princípios da economia feminista, questionou a idéia de universalismo e apontou a centralidade do cuidado e da reprodução. ${ }^{2}$ Ela convidou os demais palestrantes a debatê-los, mas eles não emitiram sequer um comentário, mesmo após a insistência de uma mulher do plenário.

No painel sobre pleno emprego e re-regulação do trabalho, o centro eram as possibilidades atuais da existência do pleno emprego. Magdalena Leon, novamente a única mulher entre homens do mundo sindical, considerou ser necessário construir uma nova visão do que pode ser o pleno emprego que tenha como um de seus eixos a igualdade de gênero, e que esta seja efetiva. Para tanto, é necessário pensar a relação entre o produtivo e o reprodutivo, e operar mudanças substantivas na organização da produção, das famílias e comunidades. ${ }^{3}$

Várias pessoas que acompanharam os debates do eixo desenvolvimento sustentável comentaram que essas duas exposições trouxeram não só conteúdos novos, mas também instigavam os demais a refazer suas exposições. Mas a interação foi muito pequena, o que demonstra a permanência de núcleos duros no pensamento de esquerda resistentes ao feminismo. O pensamento feminista tem um largo debate sobre a relação entre produção e reprodução, divisão sexual do trabalho, trabalho doméstico, inserção subordinada das mulheres no mercado de trabalho, que ainda hoje não interage com as análises, muito menos com as propostas de alternativas e estratégias do movimento antiglobalização.

Uma maneira como a Marcha Mundial das Mulheres no Brasil tem lidado com esse problema é buscar em nossa presença na agenda antiglobalização ressaltar as conexões entre o tema tratado e as relações desiguais entre mulheres e homens. Um exemplo disso é nossa participação na Campanha contra a Área de Livre Comércio das Américas. Além de estarmos envolvidas nas atividades gerais, realizamos uma série de oficinas com mulheres de bairros populares e de áreas rurais para construir nossa visão sobre a Alca. Discutimos o seu significado na economia capitalista e na relação de dominação que os EUA e suas transnacionais estabelecem conosco. Mas debatemos também a mercantilização do corpo das mulheres com o incremento do turismo sexual e o lugar de nossos países em uma divisão sexual e internacional do trabalho que tem reservado a muitas de nossas mulheres o trabalho nas maquillas e na prostituição controlada por máfias e conglomerados de empresas de turismo. Temos que nos perguntar seriamente porque ao lado de uma aparente permissividade no campo da sexualidade, com o incremento do mercado da prostituição e da pornografia, está o aumento do conservadorismo e o ataque ao direito das mulheres

\footnotetext{
${ }^{2}$ CARRASCO, 2003.

${ }^{3}$ LEÓN, 2003.
} 
de controlarem seus corpos. Temos falado em novas formas de controle sobre o corpo das mulheres com a imposição de padrões de beleza estritos. Na América Latina isso tem significado uma verdadeira febre das cirurgias plásticas, do silicone, do incremento no uso de hormônios sintéticos. Hormônios estes produzidos pelas mesmas 'indústrias da vida' que produzem agrotóxicos e sementes transgênicas. Esses são apenas exemplos de diálogos e conexões que poderíamos explorar entre diferentes movimentos sociais e que ainda não aconteceram, nem mesmo neste tão vasto espaço de troca que é o Fórum Social Mundial.

\section{Novas abordagens e desaflos organizativos}

Uma das peculiaridades dos movimentos antiglobalização é que cada ação pública tem o poder de transmitir o processo pela qual ela foi construída. Uma das histórias que se conta de Seattle é que o aparelho repressivo se chocou com essa nova forma de ação que aparentemente não é coordenada porque não tem um foco visível de coordenação: um carro de som, um dirigente dando ordens. Todas e todos os presentes estão conscientes e, portanto, implicadas na construção do que será a manifestação pública. Deve ser por isso que, dali em diante, as reuniões-alvo de protestos passaram a ser cercadas por muros e grades. A resistência pode vir de qualquer lugar, a qualquer momento e de quem menos se espera.

O FSM reflete essa forma de ação em especial nas manifestações públicas e no Acampamento da Juventude, depois chamado de Cidade das Cidades. Esses são momentos e espaços ricos em vivências e de construção de relações de confiança.

Na passeata de abertura do FSM em 2003 nós da Marcha conseguimos expressar o processo de preparação que desencadeamos. Os estandartes de abertura foram concebidos e costurados em oficinas onde refletimos sobre nossas vidas, nossas visões para o futuro e o significado do Fórum para isso. A batucada trazia um longo trabalho de reutilização de latas e mulheres aprendendo a dar o ritmo e o tom. A composição da ala era uma aliança construída com a juventude presente no Acampamento e com o movimento de lésbicas, gays e travestis.

Essa alegria e essa irreverência têm nos mantido firmes e fortes em momentos de embate como em Quito, Quebec e Cancun e estreitado nossa aliança com setores do feminismo que emergem independentes ou com poucos pontos de contato com o feminismo chamado histórico, como as anarco-feministas, os grupos de ação direta, ou as imigrantes francesas do "Nem putas, nem submissas". Interessante é pensar como surge uma nova geração de feministas também com posições políticas e estratégias diversas. Há todo um setor de jovens estudantes dos gender studies nas universidades com projetos pessoais de trabalhar em uma ONG, ou em uma instituição pública, e que tem visibilidade nos espaços feministas como a nova geração. Mas há todo um universo de grupos de ação, de discussão, fanzines, rádios livres que se reivindicam feministas que, com base na relação conosco, exigem compreender nossas posições políticas, aonde queremos chegar, sem rodeios.

Essas experiências arejam a forma como concebemos as alianças entre feministas. Tem sido comum entre nós desqualificar diferentes abordagens e expressões tratadas como divisionistas ou despolitizar o debate limitando-o a uma justaposição de agendas. Esvaziando o conteúdo político da consigna de diversidade, opera-se um procedimento de construção de agenda em que cada setor, grupo ou mulher acrescenta o seu ponto e ninguém tem legitimidade de discuti-lo sob pena de ser acusada de devota de estreitas práticas de esquerda. Ao final tem-se uma agenda imensa, carregada de contradições e que não cria nenhuma condição real de luta comum. Cada uma segue fazendo o que fazia antes, e as que podem mais (provavelmente brancas e de classe média) têm mais poder de fogo para viabilizar a sua estratégia, os seus temas com o aval da plataforma de todas. 
Essa forma de construir o debate em nada ajuda a quem se propõe a construir o feminismo como um movimento com a participação de um número cada vez maior de mulheres opinando sobre seus rumos, temas e agendas e se comprometendo com 0 conjunto das decisões.

Nós nos expressamos nas manifestações, construímos conhecimento nas oficinas, nos debates, o que é fundamental. Mas o Fórum nos desafia a ocupar outros espaços com falas públicas. Em 2003, as grandes conferências no Gigantinho funcionaram como um ponto de convergência, reunindo pessoas que queriam se sentir parte de uma coisa grande, quebrando fragmentações e isolamentos, mesmo que esta unidade fosse dada pela fala de poucos conferencistas. No entanto, os símbolos de unidade, de unir razão e emoção, ainda foram quase todos religiosos: uma oração católica, uma palavra indígena sagrada.

Nosso desafio é como construir coletivamente o que e como queremos nos comunicar com essas pessoas nesses momentos, falando e propiciando vivências não só de como é a vida das mulheres hoje, mas de como o feminismo tece alternativas para o presente e o futuro de todas e todos.

\section{Construindo alianças com os movimentos}

Também temos exercitado a construção de alianças com os movimentos sociais. Os movimentos são sujeitos coletivos constituídos que se expressam por um trabalho organizativo, pela capacidade de análise, pela agenda, por estratégias, e em um espaço de debate em condições mais ou menos igualitárias (dependem da correlação de forças e da capacidade de força de cada sujeito) coordenamos uma ação pontual, uma agenda comum, até uma estratégia comum de médio prazo.

Como Marcha, temos debatido o que são nossas alianças com o movimento social misto conformando o movimento antiglobalização e as alianças no interior do movimento feminista.

Nos primeiros debates que fizemos formulávamos a idéia de estar bem firmes sobre duas pernas; a afirmação de nossa agenda feminista no contexto das lutas antiglobalização e nossa relação com os movimentos mistos. Sabemos que, se conseguirmos nos colocar de forma autônoma e com força, não seremos engolidas em uma mobilização mais ampla. É evidente que isso coloca problemas de ordem prática: nem temos todo o tempo do mundo nem tantos recursos e temos que nos equilibrar entre nossa própria agenda e uma agenda carregada dos movimentos sociais. Nossa decisão foi de operar não com umas poucas dirigentes internacionais viajando de um lado a outro do mundo, a cada evento do movimento, mas circular informações, qualificar o debate entre nós para que cada seção da Marcha em um país se ocupasse de nossa representação e nossas responsabilidades diante dos demais movimentos no país onde acontece a ação. Nossas responsabilidades não têm sido pequenas. Depois da Via Campesina, a Marcha Mundial das Mulheres é o movimento que, com uma identidade construída ao longo de cinco anos de trabalho comum, tem mais pontos de contato no mundo.

\section{E o futuro?}

Não há quem se arrisque a falar do futuro do Fórum. Se ele é um espelho dos movimentos sociais, e em particular dos movimentos sociais globais, seria necessário assumir a difícil tarefa de pensar o futuro das principais expressões desses movimentos e das interações entre eles e ainda assim a tarefa estaria incompleta.

Quando se comenta o futuro do Fórum sempre se parte do que são suas forças e de nossa capacidade de projetá-las para frente. Há quase uma unanimidade de que a força 
do FSM vem de sua agenda - a luta contra as políticas neoliberais, a guerra e a dominação imperial - e de seu método - um espaço aberto e horizontal. ${ }^{4}$

O desafio é manter uma agenda que reflita e faça convergir as diversas expressões dos movimentos. O desafio é radicalizar o método. No documento que trata dos rumos do processo Fórum Social Mundial o Conselho Internacional saúda como positiva a multiplicação dos fóruns sociais regionais e temáticos que guardam a unidade no método. E propõe pequenos ajustes para Mumbai em 2004, fortalecendo as atividades gestionadas no equilíbrio com as atividades articuladas pelos organizadores.

Quando trata do futuro do processo FSM, José Correa Leite também destaca a questão do método:

As instâncias do Fórum ( $\mathrm{Cl}$, secretaria, CO's) têm que ser facilitadoras qualificadas, aceitar concorrências e conflitos de papéis, lidar pacientemente com disputas, estar permeáveis aos influxos do movimento e resistir a tentação de suprimirem as contradições e se assumirem como direção. ${ }^{5}$

Considerando que o método é considerado uma das bases do processo Fórum, seria interessante resgatar o percurso do debate organizativo do próprio Fórum e do movimento antiglobalização. Sobre os movimentos sociais no FSM de 2002 houve a conferência "Perspectivas sobre o movimento global da sociedade civil", que identificou como protagonistas dessa nova onda de ascenso jovens, mulheres e trabalhadores. (Nada disseram sobre camponeses.) O consenso se deu em torno de uma estratégia de desobediência civil não violenta. Em 2003 o eixo "Poder político, sociedade civil e democracia" abrigou três painéis, que por seus objetivos desdobrariam a conferência de 2002. Com representação de diversos movimentos sociais o centro do debate eram as "estratégias de confluência, complementariedades e equivalências na construção de alianças amplas que universalizam o particular". Um painel tinha por título a insurgência tratada como uma maneira de efetivar a ampliação dos limites da cidadania.

Porém, em nenhum momento foi previsto um olhar sobre o processo organizativo do próprio Fórum e de suas edições locais. O Fórum Social Europeu, por exemplo, trouxe inovações importantes e positivas ao utilizar como método a construção em plenárias abertas e periódicas realizadas em várias cidades de diferentes regiões do continente, atraindo sempre novas organizações e recolhendo propostas.

Isto que para alguns pode ser muito "improdutivo" ou "anárquico" se revelou, ao contrário, muito "eficiente" no que o FSM busca: a mais ampla participação (conseguindo incorporar inclusive aqueles movimentos que por suas características não se fazem representar em âmbito internacional, continental ou nacional). É o que um companheiro da Via Campesina chamou de "valor positivo de nosso método ineficiente". E como neste mundo as idéias dominantes são as idéias da classe dominante, muitas vezes usamos como critério de "eficiência" os critérios construídos para um mundo que estamos justamente querendo combater e superar.

Esse debate organizativo também seria de grande importância para nós feministas que nos propusemos a construir um movimento horizontal. Já temos história suficiente para um balanço, e para compartir com os movimentos sociais. E temos uma sensação de esgotamento e de necessidade de atualização diante dos desafios do momento.

Quanto à outra base de sucesso do Fórum, a agenda, existe pelo menos duas

\footnotetext{
${ }^{4}$ CONSELHO INTERNACIONAL, 2003.

${ }^{5}$ LEITE, 2003.

${ }^{6}$ Gustavo CODAS, 2003, p. 17.
} 
necessidades urgentes. A primeira é que, se é correto aprofundar as análises e debates de alternativas por eixos, é preciso inter-relacionar esses eixos. O movimento feminista poderia se propor a não só intervir em cada um dos debates como também estabelecer os vínculos entre eles tendo o feminismo como fio que conduz e costura. A segunda é aprofundar os nexos entre os temas e conjunturas globais e locais de modo a alimentar os movimentos em suas lutas cotidianas, mas também resgatar de cada questão nacional sua dimensão de humanidade. Isso nos remeteria à construção de uma nova idéia e valor de igualdade, promessa jamais cumprida pela Revolução Francesa. Célia Amorós, na conferência sobre princípios e valores no FSM de 2002, afirmou que o pensamento feminista elaborou de forma notável a idéia de igualdade, a qual permanece como o "teste sine qua non com o que se há de contrastar sempre a sensibilidade e o comportamento da esquerda". ${ }^{7}$

O futuro do Fórum Social Mundial está intimamente ligado com o futuro que traçamos para nós mesmas e nossos movimentos. Nosso horizonte segue sendo a transformação e a igualdade.

\section{Referencias bibliográficas}

AMORÓS, Célia. "El feminismo y la tríada de los ideales ilustrados". Documento de la web 2002: <www.forumsocialmundial.org.br>.

CARRASCO, Cristina. "Para otra economía: una visión desde la economía feminista". In: FARIA, Nalu (Comp.). Construir la igualdad: debates feministas en el Foro Social Mundial. São Paulo: REMTE-SOF, 2003. p. 29-43.

CODAS, Gustavo. "Cuál es el papel del Foro Social Mundial?" Alternativas. Revista de análisis y reflexión teológica, Manágua: Editorial Lascasiana, ano 10, n. 25, 2003. p. 13-22.

CONSELHO INTERNACIONAL (Cl). "Os rumos do processo Fórum Social Mundial,". Documento de la web 2003: <www.forumsocialmundial.org.br>.

HIRATA, Helena. "Pour qui sonnent les glas? Mondialisation et division sexuelle du travail". In: BISILLIAT, Jeanne (Dir.). Regards des femmes sur la globalisation. Paris: E. Karthala, 2003. p. 11-16.

KERGOAT, Danièle. "Division sexuelle du travail et rapports sociaux de sexe". In: HIRATA, Helena; LABORIE, Françoise; LE DOARÉ, Hélène; SENOTIER, Danièle (Coords.). Dictionnaire critique du féminisme. Paris: Ed. PUF, 2000. p. 35-44.

LEITE, José Corrêa. Fórum Social Mundial: a história de uma invenção política. São Paulo: Ed. Fundação Perseu Abramo, 2003.

LEÓN, Magdalena. "Pleno empleo y el trabajo de las mujeres". In: FARIA, Nalu (Comp.). Construir la igualdad: debates feministas en el Foro Social Mundial. São Paulo: REMTESOF, 2003. p. 19-28.

\footnotetext{
${ }^{7}$ AMORÓS, 2002.
} 
Feminism in Motion: Issues and Organising Processes of the World March of Women in the World Social Forum

Abstract: The text presents a comparisson among the raising and development of the World Social Forum and of the World March of Women in Brazil. The Forum has had an enormous contribution to historicize the capitalist globalization and to change the terms of the debate, and the women's movement has its trajectory embeded in this context, as well as the great potential that feminism has to denaturalize the mainstream vision on globalization and neoliberal economy. The text also presents the relation built among the movements and their common agendas that has being expressed in the framework of the anti-globalization movement actions. Key words: women, feminism, social movements, politics. 